\title{
OPEN Valorization of Colombian fique (Furcraea bedinghausii) for production of cellulose nanofibers and its application in hydrogels
}

Marcelo A. Guancha-Chalapud ${ }^{1}$, Jaime Gálvez ${ }^{1}$, Liliana Serna-Cock ${ }^{2} \&$ Cristobal N. Aguilar $^{3 凶}$

Cellulose nanofibers were obtained from the Colombian fique (Furcraea bedinghausii) and Acrylic hydrogels $(\mathrm{H})$ and reinforced acrylic hydrogels with fique nanofibres (HRFN) were synthesized, using the solution polymerization method. The extraction was carried out using a combined extraction method (chemical procedures and ultrasound radiation). The raw material (NAT-F), bleached fibers (B-F), hydrolyzed fibers and fibers treated with ultrasound (US-F) were characterized by infrared spectroscopy (FTIR) and thermal stability analysis; also, in order to have a comparison criterion, a commercial microcrystalline cellulose sample (CC) was analyzed, which demonstrated the extraction of fique cellulose. The surface morphology of the NAT-F and the B-F was determined by scanning electron microscopy and the average particle size of the nanofibers was made through transmission electron microscopy. In H y HRFN the strain percent and compression resistance (Rc) were measured. The fique nanofibers showed diameter and length averages of $25.2 \pm 6.2 \mathrm{~nm}$ and $483.8 \pm 283.2 \mathrm{~nm}$ respectively. Maximum degradation temperature was $317^{\circ} \mathrm{C}$. HRFN presented higher compression resistance $(16.39 \pm 4.30 \mathrm{kPa})$ and this resistance was 2.5 greater than the resistance of $\mathrm{H}$ $(6.49 \pm 2.48 \mathrm{kPa})$. The results indicate that fique lignocellulosic matrix has potential application for obtaining polymeric type composite materials.

Hydrogels are polymers with a crisscrossed three-dimensional structure which allows to absorb, store and release water molecules ${ }^{1}$. Its application is oriented to the manufacture of personal hygiene products, medical ${ }^{2,3}$, environmental ${ }^{4-6}$ and agricultural applications ${ }^{7,8}$. Hydrogels for application in agriculture are usually synthesized based on acrylates or similar monomers (acrylamide, methyl methrillate among others), because cross-linked polymers with high absorption capacity and bloating rate are obtained ${ }^{1,9}$ and low toxicity ${ }^{10,11}$. One of the main limitations of hydrogels for agricultural applications is their low mechanical strength ${ }^{10,12,13}$. The pressure exerted by the plant and the soil layer on the hydrogel influence the loss of swelling capacity, elasticity and stiffness ${ }^{14,15}$. To maintain polymer elasticity, long-chain molecules and adequate interbreeding are needed to dissipate external mechanical stresses on the hydrogel ${ }^{10,13,16}$. To improve mechanical properties, manometric-sized reinforcement materials such as: inorganic nanoclafers, carbon nanotubes, nanoparticles of inorganic compounds are usually used $^{11,17}$. However, one of the disadvantages of using reinforcement materials is the decrease in water absorption capacity ${ }^{18}$. As consequence, an alternative is the use of micro-scale cellulose and nano as a reinforcement material in hydrogels ${ }^{19}$. Several studies show that the addition of cotton nanofibers ${ }^{9,20}$, $\operatorname{chitosan}^{21}$, wood d $^{10,12,22}$ into acrylic base hydrogels, increases, mechanical strength and swelling capacity due to increased surface area, elastic character of fibers and the presence of hydroxyl groups within the polymer matrix ${ }^{22-24}$. The addition of nanofibers in hydrogels increases compression resistance by up to $50 \%^{14,22}$, and the ability to recover its original shape (elasticity) from the application of external forces, up to $80 \%$ compared to its original height ${ }^{11,14}$.

\footnotetext{
${ }^{1}$ National Center for Technical Assistance to Industry (ASTIN), Servicio Nacional de Aprendizaje - SENA, Cali, Colombia. ${ }^{2}$ Faculty of Engineering and Administration, Universidad Nacional de Colombia Campus Palmira, Palmira, Colombia. ${ }^{3}$ Bioprocesses and Bioproducts Research Group. Food Research Department, School of Chemistry. Universidad Autónoma de Coahuila, Saltillo, Mexico. ${ }^{\bowtie}$ email: cristobal.aguilar@uadec.edu.mx
} 


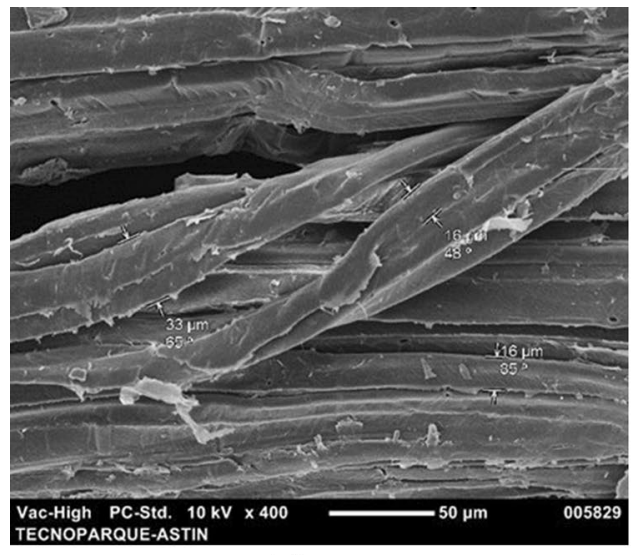

(a)

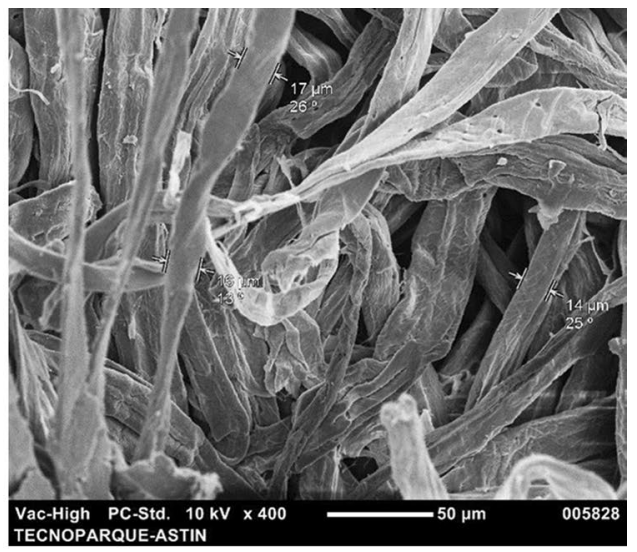

(b)

Figure 1. SEM micrographs (a) native fique (NAT-F), (b) bleached fibers (B-F).

For the use of cellulose nanofibers as reinforcing agents, cellulose sources that are available, sustainable and inexpensive should be considered, therefore, an alternative is the use of agro-industrial waste ${ }^{25}$. Agricultural activity generates a large amount of crop waste, including fique ${ }^{26}$. The fique agribusiness in Colombia focuses on the production of fibers ${ }^{27}$, however, the fibers represent only $4 \%$ of the leaves, the remaining $96 \%$ corresponds to waste generated in the process, such as juice $(70 \%)$ bagasse or cabuyasa $(30 \%)^{27,28}$. Consequently, fique lignocellulosic residues are an alternative source for nanofiber isolation. Fique fibers are characterized by their high cellulose content (50-74\%), specific strength, biodegradability ${ }^{29}$, low density $\left(1.5 \mathrm{~g} \mathrm{~cm}^{-3}\right.$ compared to fiberglass $\left.2.5 \mathrm{~g} \mathrm{~cm}^{-3}\right)^{30}$, and is considered one of the most tensile resistant (511-635 MPa) compared to other natural fibers ${ }^{31}$.

Chemical pretreatment of cellulosefibers is essential to improving nanofibrillation and decreasing energy consumption $^{25}$. These pretreatments are necessary because lignin and hemicelulose coat ${ }^{15,16,26,27}$ cellulose chains and lead to different qualities and morphologies of nanofiber ${ }^{25}$. To break the amorphous region of the chains and isolate cellulose nanofibers, several methods have been used since 2008 including acid hydrolysis, enzyme processes, oxidation, high-pressure homogenization, high-intensity ultrasound and steam blasting processes ${ }^{32}$. Recently new approaches to pretreatment have been developed that do not hydrolyze or oxidize the cellulose fibers, which include the use of deep eutectic solvent, $\mathrm{NaOH}$ swelling, Imidazole, Carboxymethyl cellulose adsorption, but their detailed mechanisms remain to be investigated ${ }^{33}$.

In the isolation of nanofibers the use of concentrated chemicals or mechanical methods for long periods of time degrade cellulose decreasing the degree of polymerization of chains $s^{34}$. The use of combined methods decreases cellulose degradation and optimizes morphology and aspect ratio ${ }^{32}$. To increase the yields in obtaining nanocellulose is required to separate cellulose chains from the crystalline part, one of the methods used for this purpose is the ultrasound technique. The transfer of ultrasonic energy to the cellulose chains generated by the cavitation process, is similar to the energy to break a hydrogen bond $(100 \mathrm{~kJ} / \mathrm{mol})$, therefore, when applying this technique can disintegrate cellulose fibers from the crystalline part, of micrometric size to nanometric size ${ }^{35,36}$.

The objectives of this paper were to obtain fique nanofibers using chemical methods combined with ultrasound radiation and to evaluate the effect of fique nanofibers as reinforcing material in acrylic hydrogels. Morover, fibers and nanofibers study was made using infrared analysis (FITR), scanning electron microscopy (SEM), transmission electron microscopy (TEM) and thermogravimetric analysis (TGA); additionally, the strain and resistance to compression of the reinforced hiydrogels are discussed.

\section{Results and discussion}

Characterization of raw material (NAT-F) and bleached fibers (B-F). Cellulose and lignin contents of NAT-F were 45,42 and $21.34 \%$ respectively, and B-F were $91.92 \%$ and $4.14 \%$ respectively. The fiber bleaching process was efficient as it managed to eliminate more than $80 \%$ of the lignin present in NAT-F. These results were similar to the results reported by Ovalle et al. ${ }^{26}$ where after the delignification process the lignin content decreased from 23.3 to $2.8 \%$ and the cellulose content increased from 52.3 to $83.6 \%$.

SEM micrographs were performed to have the particle size of the different products obtained during the nanofibrilation process from fique. The Fig. 1 shows the SEM micrographs of NAT-F and B-F. NAT-F (Fig. 1a) appears as agglutinated fibers, with a rigid appearance and an approximate diameter of $34.2 \mu \mathrm{m}$. B-F (Fig. 1b) has a surface roughness and the fiber diameter ranged from 9 to $21.4 \mu \mathrm{m}$. According to Candra et al. ${ }^{37}$ lignocellulosic materials without any treatment do not show homogeneity due to the presence of compounds such as lignin, hemicellulose, pectin, among others, which act as binders, preventing defibrillation of cellulose chains. Additionally, roughness in bleached fique fiber is due to nanofibrils which are connected through hydrogen bonds, to form larger units of microfibrils ${ }^{36,37}$. 
(a)

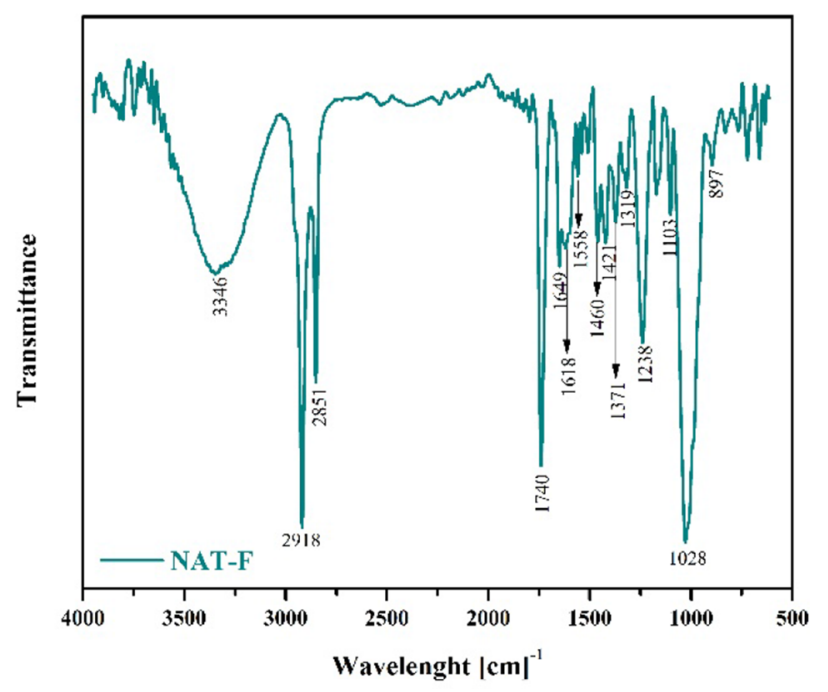

(b)

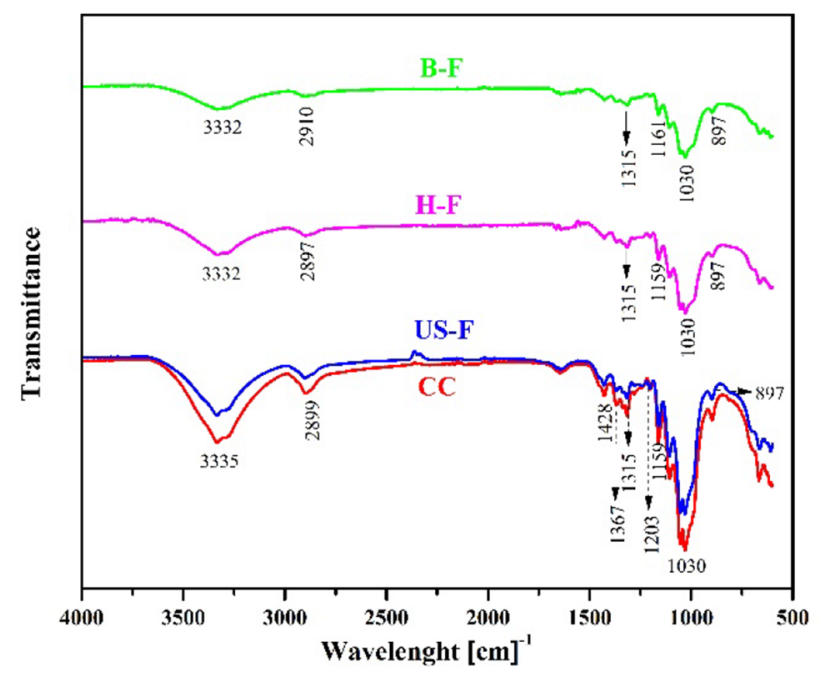

Figure 2. (a) Infrared spectrum (FITR) of untreated native fique fibers (NAT-F), (b) infrared spectra of bleached fibers (B-F), hydrolyzed fibers (H-F), fibers treated with ultrasound (US-F). Commercial.

FITR analysis. Infrared spectrum of the NAT-F is shown in Fig. 2a, b shows the FTIR spectra of B-F, H-F, US-F and CC.

Infrared spectrum of the NAT-F shows two absorption zones. The absorption band that was obtained from $3346 \mathrm{~cm}^{-1}$ for the raw material corresponds to hydroxyl groups $(-\mathrm{OH})$ and the band at $2,918 \mathrm{~cm}^{-1}$ corresponds to $\mathrm{C}-\mathrm{H}$ stretch present in cellulose, hemicellulose and lignin ${ }^{38}$. The carbonyl group band appears at $1,740 \mathrm{~cm}^{-1}$, and its correspond to bond vibration present in the ester and carboxylic groups (-COOCH 3 and $-\mathrm{COOH}$ ) characteristic of hemicellulose, ferulic and p-coumaric acids, which belongs to lignin ${ }^{38,39}$. The band at $1,238 \mathrm{~cm}^{-1}$ corresponds to $-\mathrm{C}-\mathrm{O}-\mathrm{C}-$ bond vibration present in the bonds between aromatic ring and methoxy groups in lignin ${ }^{40}$. The bands at $1,649,1,460$ and $1,421 \mathrm{~cm}^{-1}$ for raw material, corresponds to the $\mathrm{C}=\mathrm{C}$ bond stretching present in aromatic rings of lignin ${ }^{37,38,40,41}$. Finally, at $1,028 \mathrm{~cm}^{-1}$ for raw material refers to $\mathrm{C}-\mathrm{O}-\mathrm{C}$ bond stretching of $\beta$-1,4-glycosidic ring bonds among $D$-glucose units in cellulose ${ }^{37}$.

To remove the lignin, hemicelluloses, waxes and other components was applied an alkali treatment (delignification) and to remove completely the lignin the bleaching treatments was performed, obtaining B-F. The FTIR spectra of B-F, H-F, US-F and CC. B-F FTIR spectrum shows the disappearance of several peaks $(1,740$, $1,238,1,649,1,460$ y $1,421 \mathrm{~cm}^{-1}$ ) caused by the removal of lignin and hemicellulose due to chemical treatment. It should be mentioned that, in addition, an increasing in peaks intensity around 1,030, 3,332 and $2,900 \mathrm{~cm}^{-1}$, indicate the presence of cellulose and become more pronounced in the H-F and US-F spectra. It is observed, in addition, in B-F spectrum the appearance of peaks in 1,160,1,315 and $897 \mathrm{~cm}^{-1}$. Additionally, these peaks become more intense due to the effect of acid treatment followed by treatment with ultrasound radiation. The presence of peak at $1,428 \mathrm{~cm}^{-1}$ and an increasing in peaks intensity around 1,367 and $1,315 \mathrm{~cm}^{-1}$ in US-F spectrum is in line with that reported by Avolio et al. ${ }^{42}$ and Candra et al. ${ }^{37}$, where is indicated that acute signals around 1,426 and $897 \mathrm{~cm}^{-1}, 1,370$ and $2900 \mathrm{~cm}^{-1}$ reflect the crystalline band of cellulose. In addition, Fan et al. ${ }^{43}$ report that sharp peaks around 1,420 and $894 \mathrm{~cm}^{-1}$ indicate the presence of crystalline structures, a widening of these bands reflects a more disordered structure that would correspond to amorphous cellulose.

Thermogravimetric analysis. The thermogravimetric (TG) results (Fig. 3) are summarized in Table 1.

A thermal stability analysis was performed to demonstrate the efficiency of bleaching, hydrolysis acid and ultrasound treatment treatments (Fig. 3). Three stages of degradation were observed: the first, below $250{ }^{\circ} \mathrm{C}$, the second between $250{ }^{\circ} \mathrm{C}$ and $400{ }^{\circ} \mathrm{C}$ and the third above $400{ }^{\circ} \mathrm{C}$ (Fig. 3a). For all the products was found a small weight loss corresponding to the removal of moisture in the range of $25-150{ }^{\circ} \mathrm{C}$, due to water evaporation process or loss of low molecular weight compounds. In all cases, the cellulosic materials shown maximum temperature degradation from 316 to $352^{\circ} \mathrm{C}$, and a third less pronounced peak between 400 and $500{ }^{\circ} \mathrm{C}$ because of the lignin residues in the raw material and the delignificated cellulose. The initial degradation temperatures were found to be around $228,192,292,250$ and $288^{\circ} \mathrm{C}$ for the NAT-F, B-F, H-F, US-F and CC, respectively. The initial degradation temperatures of $\mathrm{H}-\mathrm{F}\left(292^{\circ} \mathrm{C}\right)$ and US-F $\left(250^{\circ} \mathrm{C}\right)$ were appreciably increased compared with the NAT-F temperature $\left(228^{\circ} \mathrm{C}\right)$ due to the partial removal of hemicelluloses, lignin and pectin by delignification and bleaching process (Fig. 3b). B-F had a shoulder between 200 and $300{ }^{\circ} \mathrm{C}$ and a slightly pronounced peak between 400 and $500{ }^{\circ} \mathrm{C}$. This shows that treatment with hydroxide and chlorite did not completely eliminate hemicellulose and lignin. Similar results were reported in cellulose nanofiber isolation from fique, where Hoyos et al. ${ }^{27}$ used $5 \% \mathrm{KOH}, 1 \% \mathrm{NaClO}_{2}$ and $1 \% \mathrm{HCl}$ as a bleaching medium. The authors demonstrated by FTIR the absence of peaks of lignin and hemicellulose in bleached fibers, however, thermogravimetric analysis showed the presence of shoulders around $300^{\circ} \mathrm{C}$ indicating the presence of traces of hemicellulose. On the other hand, the 


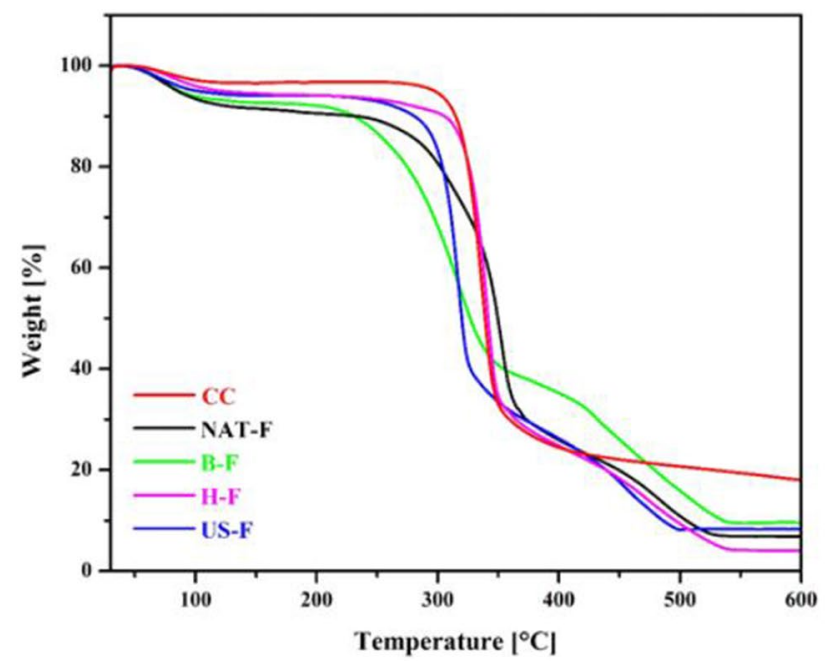

(a)

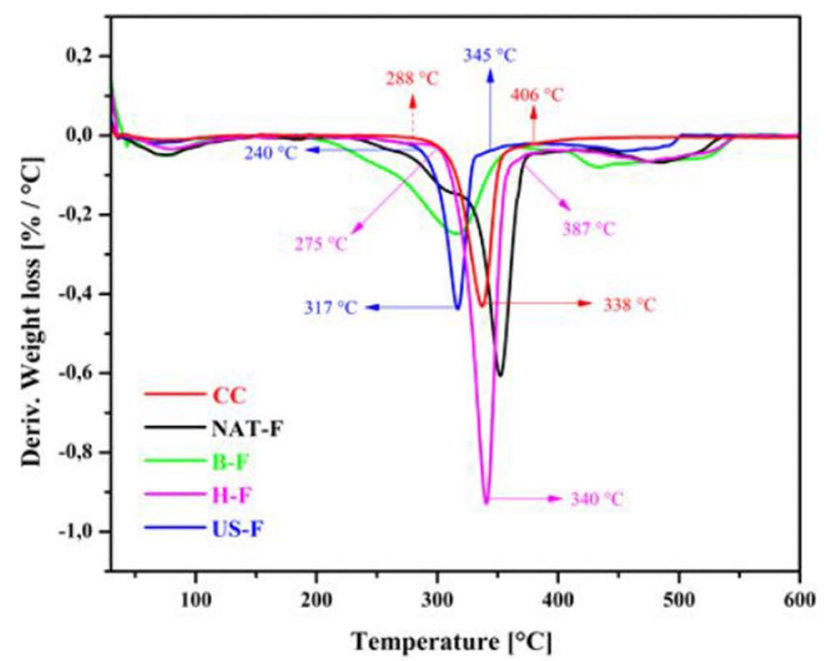

(b)

Figure 3. (a) Thermogravimetric analysis of fique fibers: native untreated fibers (NAT-F), bleached fibers (B-F), hydrolyzed fibers (H-F), fibers treated with ultrasound (US-F). Commercial cellulose (CC). (b) Derivative thermogravimetric analysis of fique fibers: native untreated fibers (NAT-F), bleached fibers (B-F), hydrolyzed fibers (H-F), fibers treated with ultrasound (US-F). Commercial cellulose (CC).

\begin{tabular}{|l|l|l|l|l|}
\hline & $\mathbf{T}_{\mathbf{0}}\left({ }^{\circ} \mathbf{C}\right)$ & $\mathbf{T}_{\max }\left({ }^{\circ} \mathbf{C}\right)$ & $\mathbf{T} 5 \%\left({ }^{\circ} \mathbf{C}\right)$ & $\mathbf{T} 10 \%\left({ }^{\circ} \mathbf{C}\right)$ \\
\hline NAT-F & 228 & 352 & 83 & 200 \\
\hline B-F & 192 & 316 & 88 & 229 \\
\hline H-F & 292 & 340 & 115 & 303 \\
\hline US-F & 250 & 317 & 107 & 278 \\
\hline CC & 288 & 337 & 295 & 314 \\
\hline
\end{tabular}

Table 1. Thermal parameters obtained TGA analysis of: untreated native fique fibers (NAT-F), bleached fibers (B-F), hydrolyzed fibers (H-F), fibers treated with ultrasound (US-F). Commercial cellulose (CC).

$\mathrm{H}-\mathrm{F}$ and US-F samples show a more pronounced point of maximum degradation temperature, $340{ }^{\circ} \mathrm{C}$ and $317^{\circ} \mathrm{C}$ respectively. The degradation temperature of $\mathrm{H}-\mathrm{F}$ is approximately to $\mathrm{DC}$, while the degradation temperature of US-F is lower than the degradation temperature of DC $\left(338^{\circ} \mathrm{C}\right)$, typical value of cellulose ${ }^{44}$. Our results are close to those reported by Ovalle et $\mathrm{al}^{26}{ }^{26}$; who obtained nanofibers from fique residues by the oxidation process with TEMPO combined with ultrasound and whose degradation temperature was $310^{\circ} \mathrm{C}$, temperature lower than the degradation temperature of the cellulose. According to previous reports ${ }^{34,45}$, the low degradation temperatures of the cellulose nanofibers is related to number of free terminal chains which decompose at lower temperatures. Therefore, in accordance with what was reported by Barbash et al. ${ }^{34}$ and Roman and Winter ${ }^{46}$, the isolation of cellulose nanofibers by hydrolysis with $\mathrm{H}_{2} \mathrm{SO}_{4}$ causes a significant decreasing in degradation temperature and an increasing in range of degradation temperature and this is due to the inclusion of sulfate groups in cellulose chains. This behavior was evident in this study. Nevertheless, Rämänen et al. ${ }^{47}$, indicate that the effect of decreasing in thermostability is decreased when sulphate groups were neutralized previously to drying process. The mentioned authors also report that drying method is another factor that influences the thermal stability of cellulose nanofibers, and reports that differences in thermostability are due to fibers reordering due to water elimination. When samples are dried in a conventional manner with air, nanofibers are free to form a homogeneous phase with a defined distance among particles. While drying process through lyophilization requires initial freezing. In lyophilization, nanofibrils cannot be rearranged during water sublimation process, obtaining clusters of dispersed nanofibers and a higher specific surface area ${ }^{47}$, which affects thermal stability. In addition, at low temperatures the fibrils regrouping occurs randomly leaving a large part of free cellulose chains ${ }^{45}$. The above mentioned is important to consider in this study since samples once the hydrolysis process was finished, they were subjected to drying in a forced convection oven and, after ultrasound treatment, they were subjected to drying through lyophilization.

Particle size. Particle sizes of $25.2 \pm 6.2 \mathrm{~nm}$ in diameter were obtained for fique nanofibers, which is evidenced in micrographs obtained from TEM analysis (Fig. 4). It is observed that the treatment with $\mathrm{H}_{2} \mathrm{SO}_{4}$ process combined with ultrasound leads to fibers individualization to diameters smaller than $100 \mathrm{~nm}$, which initially 


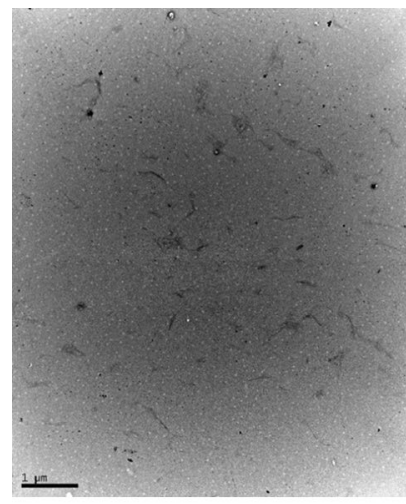

(a)

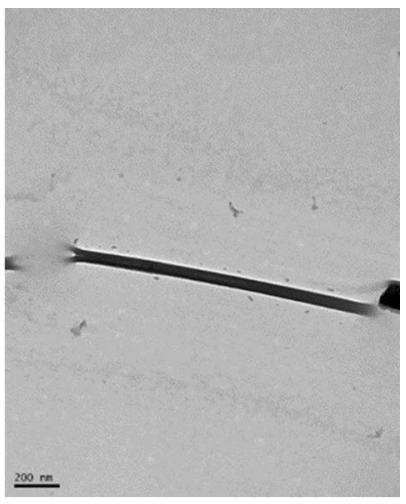

(b)

Figure 4. TEM micrographs for fique nanofibers. (a, b) Scale 1,000 and $200 \mathrm{~nm}$, respectively.

ranged from 14 to $21.4 \mu \mathrm{m}$. The results of length and aspect ratio (L/D) of the nanofibers were: $483.8 \pm 283.2$ and $19.2 \pm 12.2$ respectively.

Treatment with $\mathrm{H}_{2} \mathrm{SO}_{4}$ process combined with ultrasound leads to fibers individualization to diameters smaller than $100 \mathrm{~nm}$, which initially ranged from 14 to $21.4 \mu \mathrm{m}$. The results coincide with what was reported by ${ }^{48,49}$ where it is argued that to be considered nanofibers they must have a diameter between 10 to $100 \mathrm{~nm}$ while length ranges between 100 and $1,000 \mathrm{~nm}$.

TEM micrograph shows separated and agglomerated nanoparticles. According to what was reported by Song et. $\mathrm{al}^{50}$, agglomeration generally depends on Van der Waals attractive forces among nanoparticles. These results are comparable in variability to the report by Trifol et al. ${ }^{51}$ where fique nanofibers production with a diameter of $27.0 \mathrm{~nm}$ and length of $658 \mathrm{~nm}$ is reported.

On the other hand, the study made by Gomez et al. ${ }^{27}$ reports nanofiber sizes of fiche residues between 8 and $17 \mathrm{~nm}$ using bleaching combined with ultra-stex treatment. Similarly, Ovalle et al. ${ }^{26}$, who also worked with fique residues by the method of oxidation by TEMPO and ultrasound, found similar results. While the authors do not specify the diameter of the nanofibers exactly, it is reported that elongated and interlaced structures were obtained, with diameters of around $100 \mathrm{~nm}$ and lengths of several micrometers. Although the aforementioned authors used methodologies other than hydrolysis acid, the fiber sizes obtained show low efficiency in the separation of nanofibers from both the amorphous part and the crystalline part of the cellulose structure.

To use nanofibers as reinforcement materials length is an important parameter for determining the diameter ratio (L/D) since the value of this parameter depends on the effect on the mechanical properties on the material to be reinforced. L/D of the nanofibers were $483.8 \pm 283.2$ and $19.2 \pm 12.2$ respectively. According to Pelissari et al. ${ }^{52}$, Aspect ratio values ranged from 15.1 to 42.7 can be used as reinforcing agents in composite materials. Therefore, it can be inferred that fique nanofibers can be an alternative for material reinforcement. Likewise, the application of Colombian fique nanofibers for the synthesis of acrylic base hydrogels has not been reported. In addition, nanofibers with an L/D ratio below 60 have the capacity to form a percolated network that is maintained by hydrogen bond interactions, this contributes to an increasing in rigidity and, therefore, fibers with these characteristics have potential as reinforcement using low proportions ${ }^{53}$.

Strain percent and compression resistance of hydrogel reinforced with nanofibers. The Fig. 5 shows the stress-strain curves of hydrogels $(\mathrm{H})$ and hydrogels reinforced with fique nanofibers (HRFN). H presented Rc of $6.49 \pm 2.48 \mathrm{kPa}$ while HRFN showed an RC of $16.39 \pm 4.30 \mathrm{kPa}$.

The HRFN supported higher stresses than $\mathrm{H}$ because of the HRFN showed higher Rc $(16.39 \pm 4.30 \mathrm{kPa})$, and this value is 2.5 times better than the resistance of $\mathrm{H}(6.49 \pm 2.48 \mathrm{kPa})$. This is explained because the nanofibers interact with the polymer matrix, which favors the stability of the network ${ }^{54}$. Nanofibers dispersed uniformly in the hydrogel help to support higher loads, this could be due to the bonding between the polymer chain and the hydroxyl groups of the nanofibers ${ }^{11}$. Our results are consistent with reports that indicate that concentrations of nanofibers less than $6.7 \%$ increase the resistance to compression, higher values of nanofibers in the hydrogel reduce the dispersion of the nanofibers and decrease the crosslinking points ${ }^{14}$. Acrylamide base hydrogels have been synthesized using commercial cellulose nanocrystals of $10 \mathrm{~nm}$ in diameter and a length of $120 \mathrm{~nm}$ as reinforcement ${ }^{14}$. Similarly, Mahfoudhi and Boufi ${ }^{10}$ obtained acrylate base hydrogels-acrylamide and eucalyptus pulp nanofibers with $5 \mathrm{~nm}$ of diameter and $1 \mathrm{~mm}$ in length. The addition of these nanofibers increased the stiffness, strength and elasticity of the hydrogel. The authors also reported that at a concentration of $10 \%$ nanofibers, the elastic module and compression resistance were up to 10 and 13 times higher than hydrogel without fibers. Our study showed that the addition of fique cellulose nanofibers to hydrogels improves mechanical strength. However, the compression resistance found by Mahfoudhi and Bouf ${ }^{10}$ were considerably higher than our results.

Fique fibers in their native state are characterized by their high specific strength compared to other fibers so it could be expected that there are concentrations of fique nanofibers (different from those added to hydrogels in our research) that can generate mechanical resistances equal to or greater than that obtained by Mahfoudhi and Boufi ${ }^{10}$. This indicates that studies are required to optimize the size and concentration of fique nanofibers 


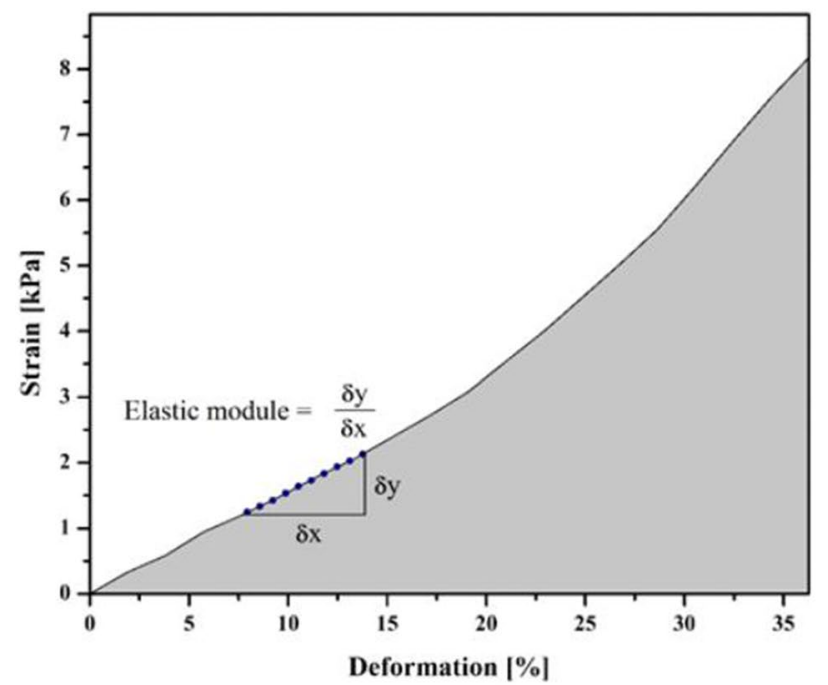

(a)

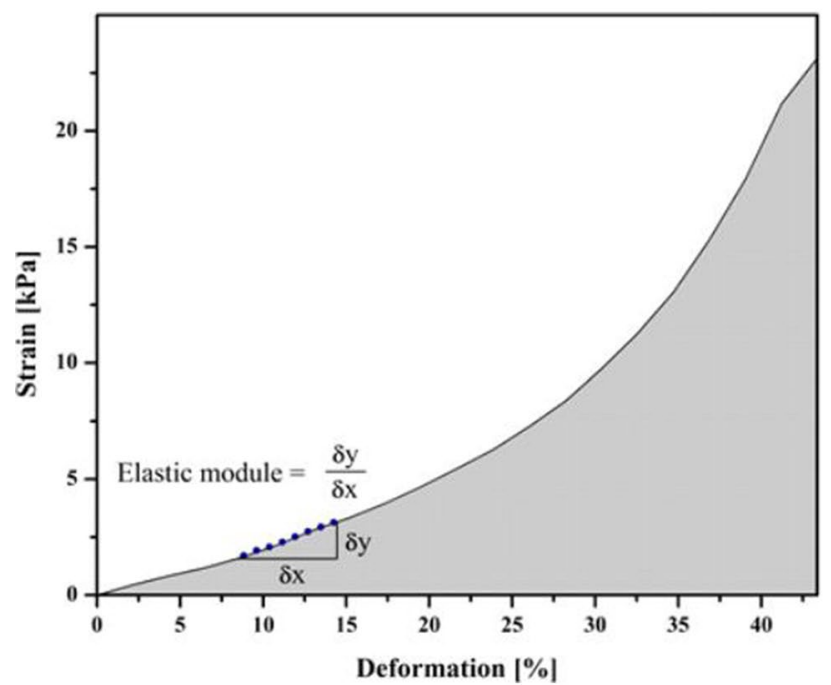

(b)

Figure 5. Strain percentage of acrylic-based hydrogels (a) hydrogel without addition of fique nanofibers, (b) hydrogel with $5 \%$ of fique nanofibers.

added to the hydrogel, and also the use of other methods of pretreating the fibers. Fique nanofibers would be an excellent environmentally friendly option to add value to waste generated in the fique production chain.

Figure 6 shows seM micrographs of $\mathrm{H}$ and $\mathrm{HRFN}$ at $3 \%$ before and after freeze-dried. HRFN shows a rougher surface (Fig. 6b, d) compared to H (Fig. 6a, c). The morphology of HRFN (Fig. 6d) is irregular, with some pores that formed during swelling and subsequent freeze-dried. According to Spagnol et al. ${ }^{20}$, the presence of cellulose nanofibers in hydrogels increases the number of hydrophilic groups, facilitating the diffusion of liquids into the matrix. Consequently, they induce the formation of pores in the structure of the polymer. In fact, the incorporation of nanofibers reduces the crossing points of the hydrogel and dilates the gaps of the network ${ }^{24}$ favoring the penetration of water within the polymer network.

Finally, in this investigation it was evident that the combined process of acid hydrolysis with ultrasound radiation allowed the obtaining of fique nanofibers with diameters less than $100 \mathrm{~nm}$. And that hydrogels reinforced with fique nanofibers considerably improved the compressive strength compared to commercial hydrogels, therefore the nanocellulose obtained from fique has great potential to be used as a reinforcing material in polymeric materials that allows to improve its mechanical properties. However, other research must be done to optimize the concentration of nanofibers needed to maximize the mechanical properties of hydrogels.

\section{Materials and methods}

Raw material preparation. The raw material was obtained in fique crops at San Bernardo (Nariño, Colombia). The samples were washed with distilled water to remove impurities. The fique was cut into pieces of approximately $1 \mathrm{~cm}$ in length. After, fique pieces were dried at $65^{\circ} \mathrm{C}$ until constant weight, then were milled in a knife mill and finally sieved to particle size of $0.5 \mathrm{~mm}$ (NAT-F).

Chemical treatment: delignification and bleaching. A mixture of NAT-F and sodium hydroxide aqueous solution $(4 \% \mathrm{w} / \mathrm{v})$ in a ratio $1: 25$ respectively, was refluxed during $4 \mathrm{~h}$ at $90{ }^{\circ} \mathrm{C}$ under mechanical stirring, washed several times with distilled water until the alkali was completely removed. Subsequently, the material obtained was bleached using a solution (1:1) of aqueous sodium chlorite $(1.7 \% \mathrm{w} / \mathrm{v})$ and acetate buffer solution ( $27 \mathrm{~g}$ of sodium hydroxide and $75 \mathrm{~mL}$ of glacial acetic acid per liter of distilled water). A mixture of delignified fiber and chlorite/buffer solution in a ratio $1: 20$ respectively, were heated at $80^{\circ} \mathrm{C}$ under mechanical stirring and reflux during $6 \mathrm{~h}$. Both, alkali and bleaching treatments were performed in duplicate. Finally, fibers were vacuum filtered, washed until neutral $\mathrm{pH}$ with distilled water and dried in a forced convection oven at $50^{\circ} \mathrm{C}$ until constant weight ${ }^{38}$.

Fiber hydrolysis and ultrasound treatment. In a bottom flask, a mixture of $5 \mathrm{~g}$ of B-F and $125 \mathrm{~mL}$ of sulfuric acid solution $\left(\mathrm{H}_{2} \mathrm{SO}_{4} 6.5 \mathrm{M}\right)$ was stirred for $24 \mathrm{~h}$ at $50{ }^{\circ} \mathrm{C}$ under reflux. Subsequently, the mixture was diluted with distilled water and neutralized with $\mathrm{NaOH} 4 \%$ until pH 6.0 to 7.0 ; the precipitate was filtered and washed with distilled water. For fibrillation process, several suspensions of the obtained cellulose $(1 \mathrm{~g})$ were prepared in distilled water $(100 \mathrm{~mL})$ and subjected to ultra-turrax treatment at 10,000 rpm during $15 \mathrm{~min}$ (H-F). The suspensions (in an ice bath) were homogenized using an ultrasonic homogenizer (BRANSON 1,510), equipped with a $1 / 2$ " diameter cylindrical probe, at a frequency of $20 \mathrm{kHz}$ with a power of $400 \mathrm{~W}$ for $30 \mathrm{~min}$. Finally, the obtained nanofiber suspensions were dried using a freeze-dryer (Labconco, Freezone 6 Plus, USA) operating with a 0.110 mbar vacuum, $48 \mathrm{~h},-40{ }^{\circ} \mathrm{C}$ condenser temperature, and $0.03{ }^{\circ} \mathrm{C} \mathrm{min}{ }^{-1}(\mathrm{US}-\mathrm{F})^{38}$. The nanofibers were stored in hermetic containers at $5{ }^{\circ} \mathrm{C}$ for further analysis. 


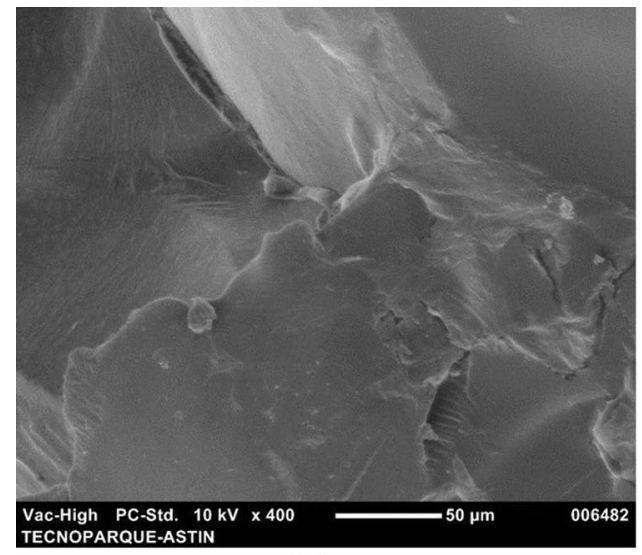

(a)

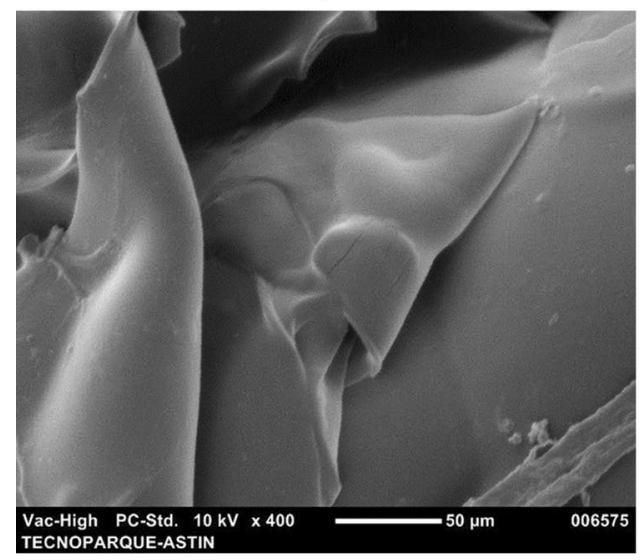

(c)

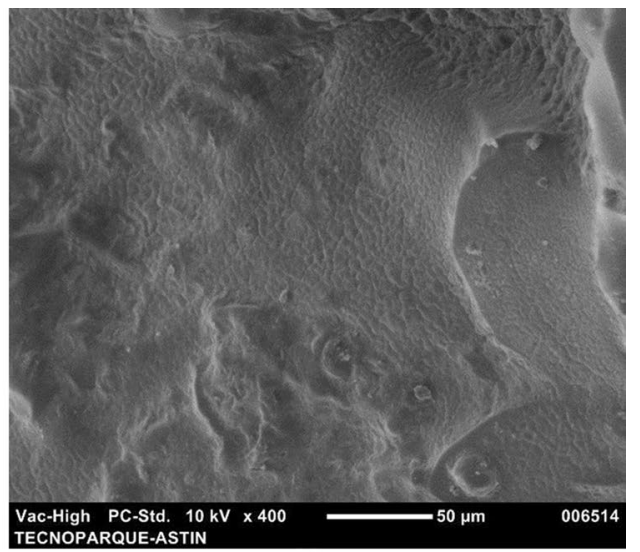

(b)

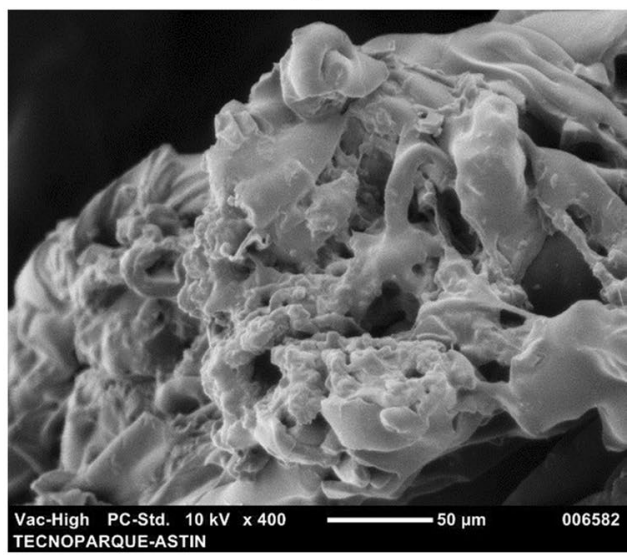

(d)

Figure 6. Micrographs (SEM) of acrylic-based hydrogels: (a) without nanofibers, (b) with 5\% of fique nanofibers, (c) lyophilized hydrogels without nanofiber, (d) lyophilized hydrogels with $5 \%$ of fique nanofibers.

Characterization of raw material (NAT-F), bleached fibers (B-F) and nanofibers (H-F and US-F). The contents of cellulose and lignin of NAT-F and B-F were determined by the method reported by Va Soes ${ }^{55}$

Scanning electron microscopy (SEM). Surface morphology from NAT-F and B-F were observed in a JEOL table microscope JCM 50000 (Japan). Previously to SEM analysis, samples were coated with gold using the high vacuum mode.

Infrared analysis (FITR). Infrared spectra were obtained for NAT-F, B-F, H-F and US-F. Fourier transform infrared (FTIR) spectra were recorded on a spectroscope (Shimadzu, Japan) in a wavelength ranged from $400-4,000 \mathrm{~cm}^{-1}$. Commercial microcrystalline cellulose (CC) was used as a control treatment.

Thermogravimetric analysis (TGA). TGA were obtained for NAT-F, B-F, H-F and US-F. In addition, TGA analysis of CC was carried out. Thermogram were obtained in a computer DSC/TGA 2STAR system, (Mettler Toledo, USA) with a temperature ranged from 30 to $600{ }^{\circ} \mathrm{C}$ at a heating rate of $10{ }^{\circ} \mathrm{C} / \mathrm{min}^{-1}$, with nitrogen supplying $\left(20 \mathrm{ml} \mathrm{min}^{-1}\right)$ and alumina crucibles with approximately $8 \mathrm{mg}$ of sample.

Diameter of particle. To determine the diameter of nanofibers, images were obtained in a transmission electron microscope (TEM) (JEOL JEM 1,011, Japan). Dispersions of $0.1 \%$ by weight nanofibers in water were prepared and mounted on copper grids. Diameters of nanofibers for each sample were estimated using the image processing software (Image J). One hundred measurements were taken to obtain the diameter distribution. The length of nanofibers was determined using Zetasizer (Malvern Instruments) and to measure length, $0.1 \%$ by weight suspensions were prepared in distilled water, which were subjected to an ultrasound bath for $30 \mathrm{~min}$. Size measurements were made in quintuplicate, using $1 \mathrm{ml}$ of suspension in a polystyrene cell with a detection angle of $90^{\circ}$ at $25^{\circ} \mathrm{C}$. 
Synthesis of hydrogel reinforced with fique nanofibers. Acrylic hydrogels $(\mathrm{H})$ and reinforced acrylic hydrogels with fique nanofibres (HRFN) were synthesized, using the solution polymerization method. Initially, suspensions of fique nanofibers were prepared in $80 \mathrm{~mL}$ of water $(0$ and $5 \%$ by weight with respect to the monomer concentration) and dispersed using Ultra Turrax at 9,000 rpm $10 \mathrm{~min}$. On the other hand, $14.0 \mathrm{~g}$ of acrylamide (AM) was mixed with $22.0 \mathrm{~g}$ of potassium acrylate (AK), obtained by neutralizing $16.0 \mathrm{~g}$ of acrylic acid (AA) with potassium hydroxide ( $\mathrm{KOH}$ ). The nanofiber solutions and the monomer solutions (AM and AK) were mixed and stirred during $10 \mathrm{~min}$ and subsequently. The initiator potassium persulfate $\left(\mathrm{K}_{2} \mathrm{~S}_{2} \mathrm{O}_{8}\right)(0.3 \%$ by weight with respect to the amount of monomers) and the crosslinker N,N-methylene bis acrylamide (NMBA) ( $0.085 \%$ by weight with respect to the amount of monomers) were added to the mixture. Finally, the suspension was refluxed in a $500 \mathrm{~mL}$ reactor, equipped with reflux condenser, under nitrogen atmosphere and magnetic stirring. The polymerization reaction was carried out at $70{ }^{\circ} \mathrm{C}$ for $6 \mathrm{~h}$. The final polymeric product was cut to reduce the size to approximately $1-2 \mathrm{~mm}$, then washed with ethanol and dried at $70{ }^{\circ} \mathrm{C}$ until constant weight ${ }^{56}$.

Mechanical properties and microscopy (SEM) of hydrogels. The maximum compression resistance $(\mathrm{Rc})$ and strain percent were performed in a universal testing machine (Goobrand $50 \mathrm{IR}$ ), according to the methodology proposed by Araki et al. ${ }^{57}$. For this, a $100 \mathrm{~N}$ load cell and a $10 \mathrm{~cm}$ diameter circular compression plate were used, at a deformation speed of $1 \mathrm{~mm} \mathrm{~min}^{-1}$. The samples were prepared according to what was proposed by Low et al. ${ }^{58}$, the samples were cut in a cylindrical shape, $25 \times 25 \mathrm{~mm}$, at their maximum swelling capacity. Strain percent and Rc were measured in triplicate.

$\mathrm{H}$ and HRFN al 3\% was observed with a scanning electron microscope (JEOL JSM6490) with an acceleration voltage of $20 \mathrm{kV}$ and high vacuum conditions. Additionally, samples were embedded in resin, their water content was extracted by lyophilization and were coated with gold to study their morphology.

Received: 27 February 2020; Accepted: 18 June 2020

Published online: 15 July 2020

\section{References}

1. Milani, P., França, D., Balieiro, A. G. \& Faez, R. Polymers and its applications in agriculture. Polímeros 27, 256-266 (2017).

2. Du, H. et al. Cellulose nanocrystals and cellulose nanofibrils based hydrogels for biomedical applications. Carbohydr. Polym. 209, 130-144 (2019).

3. Wang, Y., Cao, H. \& Wang, X. Synthesis and characterization of an injectable $\varepsilon$-polylysine/carboxymethyl chitosan hydrogel used in medical application. Mater. Chem. Phys. 248, 122902 (2020).

4. Motamedi, E., Motesharezedeh, B., Shirinfekr, A. \& Samar, S. M. Synthesis and swelling behavior of environmentally friendly starch-based superabsorbent hydrogels reinforced with natural char nano/micro particles. J. Environ. Chem. Eng. 8, 103583 (2020).

5. Kong, Y., Zhuang, Y. \& Shi, B. Tetracycline removal by double-metal-crosslinked alginate/graphene hydrogels through an enhanced Fenton reaction. J. Hazard. Mater. 382, 121060 (2020).

6. Qureshi, U. A. et al. A comparative study and evaluation of magnetic and nonmagnetic hydrogels towards mitigation of di butyl and di ethyl hexyl phthalate from aqueous solutions. J. Taiwan Inst. Chem. Eng. 59, 578-589 (2016).

7. Agaba, H., Orikiriza, L. J. B., Obua, J., Kabasa, J. D. \& Worbes, M. Hydrogel amendment to sandy soil reduces irrigation frequency and improves the biomass of Agrostis stolonifera. Agric. Sci. 2, 544-550 (2011).

8. Liang, X., Huang, Z., Zhang, Y., Hu, H. \& Liu, Z. Synthesis and properties of novel superabsorbent hydrogels with mechanically activated sugarcane bagasse and acrylic acid. Polym. Bull. 70, 1781-1794 (2013).

9. Wen, Y. et al. Development of poly (acrylic acid)/nanofibrillated cellulose superabsorbent composites by ultraviolet light induced polymerization. Cellulose https://doi.org/10.1007/s10570-015-0639-6 (2015).

10. Mahfoudhi, N. \& Boufi, S. Poly (acrylic acid-co-acrylamide)/cellulose nanofibrils nanocomposite hydrogels: effects of CNFs content on the hydrogel properties. Cellulose 23, 3691-3701 (2016).

11. Zhou, C. \& Wu, Q. A novel polyacrylamide nanocomposite hydrogel reinforced with natural chitosan nanofibers. Colloids Surf. B Biointerfaces 84, 155-162 (2011).

12. Guilherme, M. R. et al. Superabsorbent hydrogels based on polysaccharides for application in agriculture as soil conditioner and nutrient carrier: a review. Eur. Polym. J. 72, 365-385 (2015).

13. Demitri, C., Scalera, F., Madaghiele, M., Sannino, A. \& Maffezzoli, A. Potential of cellulose-based superabsorbent hydrogels as water reservoir in agriculture. Int. J. Polym. Sci. 2013, 1-6 (2013).

14. Zhou, C., Wu, Q., Yue, Y. \& Zhang, Q. Application of rod-shaped cellulose nanocrystals in polyacrylamide hydrogels. J. Colloid Interface Sci. 353, 116-123 (2011).

15. Feng, H., Li, J. \& Wang, L. Preparation of biodegradable flax shive cellulose-based superabsorbent polymer under microwave irradiation. BioResources 5, 1484-1495 (2010).

16. Sannino, A., Demitri, C. \& Madaghiele, M. Biodegradable cellulose-based hydrogels: design and applications. Materials (Basel) 2, 353-373 (2009).

17. Rashidzadeh, A., Olad, A. \& Reyhanitabar, A. Hydrogel/clinoptilolite nanocomposite-coated fertilizer: swelling, water-retention and slow-release fertilizer properties. Polym. Bull. 72, 2667-2684 (2015).

18. Zhang, S. et al. Organic/inorganic superabsorbent hydrogels based on xylan and montmorillonite. J. Nanomater. $2014,675035$. https://doi.org/10.1155/2014/675035 (2014).

19. Rodrigues, et al. Superabsorbent hydrogel composites with a focus on hydrogels containing nanofibers or nanowhiskers of cellulose and chitin. J. Appl. Polym. Sci. https://doi.org/10.1002/app.39725 (2013).

20. Spagnol, C. et al. Nanocomposites based on poly(acrylamide-co-acrylate) and cellulose nanowhiskers. Eur. Polym. J. 48, 454-463 (2012).

21. Nitta, S., Kaketani, S. \& Iwamoto, H. Development of chitosan-nanofiber-based hydrogels exhibiting high mechanical strength and pH-responsive controlled release. Eur. Polym. J. 67, 50-56 (2015).

22. Aouada, F. A., de Moura, M. R., Orts, W. J. \& Mattoso, L. H. C. Preparation and characterization of novel micro- and nanocomposite hydrogels containing cellulosic fibrils. J. Agric. Food Chem. 59, 9433-9442 (2011).

23. Spagnol, C. et al. Superabsorbent hydrogel nanocomposites based on starch-g-poly (sodium acrylate) matrix filled with cellulose nanowhiskers. Cellulose 19, 1225-1237 (2012).

24. Zhou, Y., Fu, S., Zhang, L. \& Zhan, H. Superabsorbent nanocomposite hydrogels made of carboxylated cellulose nanofibrils and CMC-g-p(AA-co-AM). Carbohydr. Polym. 97, 429-435 (2013). 
25. Duque-Acevedo, M., Belmonte-Ureña, L. J., Cortés-García, F. J. \& Camacho-Ferre, F. Agricultural waste: review of the evolution, approaches and perspectives on alternative uses. Glob. Ecol. Conserv. 22, e00902 (2020).

26. Ovalle-Serrano, S. A., Gómez, F. N., Blanco-Tirado, C. \& Combariza, M. Y. Isolation and characterization of cellulose nanofibrils from Colombian fique decortication by-products. Carbohydr. Polym. 189, 169-177 (2018).

27. Hoyos, C. G., Zuluaga, R., Gañán, P., Pique, T. M. \& Vazquez, A. Cellulose nanofibrils extracted from fique fibers as bio-based cement additive. J. Clean. Prod. 235, 1540-1548 (2019).

28. MAVDT. Guía ambiental del subsector fiquero (Federación Nacional de Cultivadores y Artesanos del Fique, Sociedad de Agricultores de Colombia, Bogotá author Ministerio del Medio Ambiente, Bogotá, Colombia, 2006).

29. Morán, J. I., Alvarez, V. A., Cyras, V. P. \& Vázquez, A. Extraction of cellulose and preparation of nanocellulose from sisal fibers. Cellulose 15, 149-159 (2008).

30. Gomez, T. S., Navacerrada, M. A., Díaz, C. \& Fernández-Morales, P. Fique fibres as a sustainable material for thermoacoustic conditioning. Appl. Acoust. 164, 107240 (2020).

31. Jose, C. \& George, K. E. Sisal nanofibril reinforced polypropylene/polystyrene blends: morphology, mechanical, dynamic mechanical and water transmission studies. Ind. Crops Prod. 71, 173-184 (2015).

32. Abdul Khalil, H. P. S. et al. Production and modification of nanofibrillated cellulose using various mechanical processes: a review. Carbohydr. Polym. 99, 649-665 (2014).

33. Rol, F., Belgacem, M. N., Gandini, A. \& Bras, J. Recent advances in surface-modified cellulose nanofibrils. Prog. Polym. Sci. 88, 241-264 (2019).

34. Barbash, V. A. et al. Effect of mechanochemical treatment of cellulose on characteristics of nanocellulose films. Proc. Phys. 183, 513-521 (2016).

35. Chen, W. et al. Individualization of cellulose nanofibers from wood using high-intensity ultrasonication combined with chemical pretreatments. Carbohydr. Polym. 83, 1804-1811 (2011).

36. Sosiati, H., Wijayanti, D. A., Triyana, K. \& Kamiel, B. Morphology and crystallinity of sisal nanocellulose after sonication. AIP Conf. Proc. 1877, 030003 (2017).

37. Candra, J., George, N. \& Narayanankutty, S. Isolation and characterization of cellulose nanofibrils from arecanut husk fibre. Carbohydr. Polym. https://doi.org/10.1016/j.carbpol.2016.01.015 (2016).

38. Zhang, P. P. et al. Effects of acid treatments on bamboo cellulose nanocrystals. Asia Pac. J. Chem. Eng. https://doi.org/10.1002/apj (2014).

39. Li, R. et al. Cellulose whiskers extracted from mulberry: a novel biomass production. Carbohydr. Polym. 76, 94-99 (2009).

40. Xie, J. et al. Isolation and characterization of cellulose nanofibers from bamboo using microwave liquefaction combined with chemical treatment and ultrasonication. Carbohydr. Polym. 151, 725-734 (2016).

41. Xie, J. et al. Characterization of microwave liquefied bamboo residue and its potential use in the generation of nano fibrillated cellulosic fiber. ACS Sustain. Chem. Eng. https://doi.org/10.1021/acssuschemeng.6b00497 (2016).

42. Avolio, R. et al. A multitechnique approach to assess the effect of ball milling on cellulose. Carbohydr. Polym. 87, 265-273 (2012).

43. Fan, M., Dai, D. \& Huang, B. Fourier transform infrared spectroscopy for natural fibres. In Fourier Transform-Materials Analysis (ed. Salih, S.) (InTech, London, 2012)

44. Vera, F. L., Cortes, H. A. M., Murcia, C. V. \& Galvis, I. C. Modificación superficial de micro fibras de celulosa obtenidas a partir de bagazo de caña de azúcar usando silanización. Informador técnico, 78(2), 106-114 (2014).

45. Hashaikeh, R. \& Abushammala, H. Acid mediated networked cellulose: preparation and characterization. Carbohydr. Polym. 83, 1088-1094 (2011).

46. Roman, M. \& Winter, W. T. Effect of sulphate groups from sulphuric acid hydrolysis on the thermal degradation behaviour of bacterial cellulose. Biomacromol 5, 1671-1677 (2004).

47. Rämänen, P., Penttilä, P. A., Svedström, K., Maunu, S. L. \& Serimaa, R. The effect of drying method on the properties and nanoscale structure of cellulose whiskers. Cellulose 19, 901-912 (2012).

48. Vieyra, H. et al. Optimized monitoring of production of cellulose nanowhiskers from Opuntia ficus-indica (Nopal Cactus). Int. J. Polym. Sci. 2015, 871345. https://doi.org/10.1155/2015/871345 (2015).

49. Trifol, J. et al. Chemically extracted nanocellulose from sisal fibres by a simple and industrially relevant process. Cellulose 24, 107-118 (2017).

50. Song, Y. K., Chew, I. M. L., Choong, T. S. Y., Tan, J., \& Tan, K. W. Isolation of Nanocrystalline Cellulose from oil palm empty fruit bunch-A response surface methodology study. In MATEC Web of Conferences, Vol. 60, 04009 (EDP Sciences, 2016).

51. Trifol Guzman, J. et al. General rights chemically extracted nanocellulose from sisal fibres by a simple and industrially relevant process chemically extracted nanocellulose from sisal fibres by a simple and 1 industrially relevant process. Citation https://doi. org/10.1007/s10570-016-1097-5 (2017).

52. Pelissari, F. M., Sobral, P. J. D. A. \& Menegalli, F. C. Isolation and characterization of cellulose nanofibers from banana peels. Cellulose 21, 417-432 (2014).

53. Lee, K. Y., Aitomäki, Y., Berglund, L. A., Oksman, K. \& Bismarck, A. On the use of nanocellulose as reinforcement in polymer matrix composites. Compos. Sci. Technol. 105, 15-27 (2014).

54. Yang, J., Han, C. R., Duan, J. F., Xu, F. \& Sun, R. C. Mechanical and viscoelastic properties of cellulose nanocrystals reinforced poly(ethylene glycol) nanocomposite hydrogels. ACS Appl. Mater. Interfaces 5, 3199-3207 (2013).

55. Van Soest, P. J., Robertson, J. B. \& Lewis, B. A. Methods for dietary fiber, neutral detergent fiber, and nonstarch polysaccharides in relation to animal nutrition. J. Dairy Sci. 74, 3583-3597 (1991).

56. Zhong, K., Zheng, X. L., Mao, X. Y., Lin, Z. T. \& Jiang, G. B. Sugarcane bagasse derivative-based superabsorbent containing phosphate rock with water-fertilizer integration. Carbohydr. Polym. 90, 820-826 (2012).

57. Araki, J., Yamanaka, Y. \& Ohkawa, K. Chitin-chitosan nanocomposite gels: reinforcement of chitosan hydrogels with rod-like chitin nanowhiskers. Polym. J. 44, 713-717 (2012).

58. Low, Z. W., Chee, P. L., Kai, D. \& Loh, X. J. The role of hydrogen bonding in alginate/poly(acrylamide-co-dimethylacrylamide) and alginate/poly(ethylene glycol) methyl ether methacrylate-based tough hybrid hydrogels. RSC Adv. 5, 57678-57685 (2015).

\section{Acknowledgements}

To Universidad Nacional de Colombia campus Palmira, to La Tour company, to ASTIN-SENA, for the funding of this research. In addition, thanks to Research Group on Materials and Products Development (GIDEMP), to biotechnology laboratories of Tecnoparque Nodo Cali, and to SENA apprentices of the Technology in Chemistry Applied to the Industry.

\section{Author contributions}

We present the article entitled "Valorization of Colombian fique (Furcraea bedinghausii) for production of cellulose nanofibers and its application in hydrogels", so that it can be submitted to reviewers. In the same way we declare that we do not have a conflict of interest in the writing and publication of this manuscript. The contribution of each author to the manuscript was M. A.G.-C. conducted the experimentation. J.A.G.-N. revised 
the English language. L.S.C. directed the experimentation, reviewed and corrected the article. C.N.A. reviewed the article and got the financial resources for the payment of the publication. Finally, I declare that all authors agree with the evaluation by the journal and grant permission to reproduce the information presented in the manuscript.

\section{Competing interests}

The authors declare no competing interests.

\section{Additional information}

Correspondence and requests for materials should be addressed to C.N.A.

Reprints and permissions information is available at www.nature.com/reprints.

Publisher's note Springer Nature remains neutral with regard to jurisdictional claims in published maps and institutional affiliations.

(c) (i) Open Access This article is licensed under a Creative Commons Attribution 4.0 International License, which permits use, sharing, adaptation, distribution and reproduction in any medium or format, as long as you give appropriate credit to the original author(s) and the source, provide a link to the Creative Commons license, and indicate if changes were made. The images or other third party material in this article are included in the article's Creative Commons license, unless indicated otherwise in a credit line to the material. If material is not included in the article's Creative Commons license and your intended use is not permitted by statutory regulation or exceeds the permitted use, you will need to obtain permission directly from the copyright holder. To view a copy of this license, visit http://creativecommons.org/licenses/by/4.0/.

(c) The Author(s) 2020 